\title{
Ivermectin susceptibility, sporontocidal effect, and inhibition of time to re-feed in the Amazonian malaria vector Anopheles darlingi
}

\author{
Kevin C. Kobylinski ${ }^{1} 2^{*}$, Karín S. Escobedo-Vargas ${ }^{3}$, Victor M. López-Sifuentes ${ }^{3}$, Salomón Durand ${ }^{4}$, \\ Edward S. Smith ${ }^{4}$, G. Christian Baldeviano ${ }^{4}$, Robert V. Gerbasi ${ }^{5}$, Sara-Blythe Ballard ${ }^{6}$, Craig A. Stoops ${ }^{3}$ \\ and Gissella M. Vásquez ${ }^{3}$
}

\begin{abstract}
Background: Outdoor malaria transmission hinders malaria elimination efforts in the Amazon region and novel vector control tools are needed. Ivermectin mass drug administration (MDA) to humans kills wild Anopheles, targets outdoor-feeding vectors, and can suppress malaria parasite transmission. Laboratory investigations were performed to determine ivermectin susceptibility, sporontocidal effect and inhibition of time to re-feed for the primary Amazonian malaria vector, Anopheles darlingi.

Methods: To assess ivermectin susceptibility, various concentrations of ivermectin were mixed in human blood and fed to An. darlingi. Mosquito survival was monitored daily for 7 days and a non-linear mixed effects model with Probit analysis was used to calculate lethal concentrations of ivermectin that killed $50 \%\left(\mathrm{LC}_{50}\right), 25 \%\left(\mathrm{LC}_{25}\right)$ and $5 \%\left(\mathrm{LC}_{5}\right)$ of mosquitoes. To examine ivermectin sporonticidal effect, Plasmodium vivax blood samples were collected from malaria patients and offered to mosquitoes without or with ivermectin at the $\mathrm{LC}_{50}, \mathrm{LC}_{25}$ or $\mathrm{LC}_{5}$. To assess ivermectin inhibition of mosquito time to re-feed, concentrations of ivermectin predicted to occur after a single oral dose of $200 \mu \mathrm{g} / \mathrm{kg}$ ivermectin were fed to An. darlingi. Every day for 12 days thereafter, individual mosquitoes were given the opportunity to re-feed on a volunteer. Any mosquitoes that re-blood fed or died were removed from the study.

Results: Ivermectin significantly reduced An. darlingi survivorship: 7-day- $-\mathrm{LC}_{50}=43.2 \mathrm{ng} / \mathrm{ml}[37.5,48.6]$, $-\mathrm{LC}_{25}=27.8 \mathrm{ng} / \mathrm{ml}[20.4,32.9]$ and $-\mathrm{LC}_{5}=14.8 \mathrm{ng} / \mathrm{ml}[7.9,20.2]$. Ivermectin compound was sporontocidal to $P$. vivax in An. darlingi at the $\mathrm{LC}_{50}$ and $\mathrm{LC}_{25}$ concentrations reducing prevalence by 22.6 and $17.1 \%$, respectively, but not at the $\mathrm{LC}_{5}$. Oocyst intensity was not altered at any concentration. Ivermectin significantly delayed time to re-feed at the 4-h $(48.7 \mathrm{ng} / \mathrm{ml})$ and $12-\mathrm{h}(26.9 \mathrm{ng} / \mathrm{ml})$ concentrations but not $36-\mathrm{h}(10.6 \mathrm{ng} / \mathrm{ml})$ or $60-\mathrm{h}(6.3 \mathrm{ng} / \mathrm{ml})$.

Conclusions: Ivermectin is lethal to An. darlingi, modestly inhibits sporogony of P. vivax, and delays time to re-feed at concentrations found in humans up to $12 \mathrm{~h}$ post drug ingestion. The $\mathrm{LC}_{50}$ value suggests that a higher than standard dose $(400-\mu \mathrm{g} / \mathrm{kg})$ is necessary to target An. darlingi. These results suggest that ivermectin MDA has potential in the Amazon region to aid malaria elimination efforts.
\end{abstract}

Keywords: Ivermectin, Anopheles darlingi, Plasmodium vivax, Amazon

\footnotetext{
*Correspondence: kobylinskikevin@yahoo.com

1 Department of Entomology, Armed Forces Research Institute of Medical

Sciences, 315/6 Rajvithi Road, Bangkok 10400, Thailand

Full list of author information is available at the end of the article
} 


\section{Background}

Malaria incidence is declining globally and rates are falling in South America. Increased malaria control measures and access to effective artemisinin combination therapy for Plasmodium falciparum are attributed to this reduction, with Plasmodium vivax now being more prevalent than P. falciparum in the Americas, including the Amazon region [1,2]. Anopheles darlingi is considered the primary malaria vector in the Amazon region [3]. Vector control is complicated by the exophagic and exophilic tendencies of An. darlingi combined with the fact that it typically occurs in recently cleared areas of the jungle where people may have limited access to vector control measures and health care [4-8]. Therefore, developing novel vector control strategies which can target exophagic and exophilic malaria vectors such as An. darlingi is essential to malaria elimination efforts in South America.

Numerous laboratory studies $[9,10]$, animal studies, and clinical trials $[11,12]$ have demonstrated that ivermectin is lethal to more than a dozen species of Anopheles worldwide. Ivermectin mass drug administration (MDA) has been suggested as a possible malaria parasite transmission control tool as it directly targets the vector at the point of human blood feeding, making it one of the few vector control tools under investigation that can directly target outdoor malaria transmission. Ivermectin MDAs in West Africa $[13,14]$ and the South Pacific $[15,16]$ validated that ivermectin is lethal to wild Anopheles at human-relevant concentrations. Furthermore, the ivermectin MDAs in Senegal, Liberia and Burkina Faso demonstrated that ivermectin can suppress $P$. falciparum transmission by wild Anopheles gambiae s.l. [14, 17]. In addition to mosquitolethal effects, ivermectin at mosquito-sub-lethal concentrations affects additional parameters of vectorial capacity by inhibiting Plasmodium development in the vector [9, $18,19]$ and delaying mosquito time to re-feed [20].

Ivermectin MDA campaigns have been performed in Central and South America for onchocerciasis elimination efforts by the Onchocerciasis Elimination Programme for the Americas (OEPA). These MDAs have been very effective at reducing Onchocerca volvulus transmission and have now eliminated the parasite from 11 of the 13 original foci [21-25]. Initially ivermectin MDAs for onchocerciasis were performed once or twice per year in Latin America. Later, it was determined that ivermectin could be given safely every 3 months [26] with quarterly MDAs effectively reducing transmission burden when nearing elimination [27]. Policy was changed and ivermectin MDAs have been deployed up to four times annually at various onchocerciasis elimination foci in Latin America [21]. This illustrates that frequent ivermectin MDAs with effective population coverage can be orchestrated in Latin America, and suggests that the more frequent ivermectin MDAs required to suppress malaria transmission [28] could be possible.
Before ivermectin MDAs for malaria parasite transmission suppression can be implemented in Latin America, the effects of ivermectin on key malaria vectors in the region, such as $A n$. darlingi, must be evaluated. Laboratory studies were conducted to investigate the effect of ivermectin compound on An. darlingi survivorship, $P$. vivax development in An. darlingi and whether ivermectin delays the An. darlingi time to re-feed.

\section{Methods \\ Mosquitoes}

All An. darlingi were reared at the Naval Medical Research Unit No. 6 (NAMRU-6) in Iquitos, Peru as described previously [29]. Larvae were raised in the larvae insectary room $\left(26.8 \pm 0.7{ }^{\circ} \mathrm{C}\right.$ and $76.1 \pm 6.3 \%$ relative humidity, and 12 -h light:12-h dark photoperiod) and adults were maintained in the adult insectary room $\left(25.9 \pm 0.8^{\circ} \mathrm{C}\right.$ and $69.7 \pm 5.7 \%$ relative humidity, and 12-h light:12-h dark photoperiod). Adult mosquitoes used for experiments were provided with $10 \%$ sucrose solution ad libitum. Mosquitoes used for experiments were between 3 and 5 days post emergence and mosquitoes were sugar starved with access to water from 18 to $22 \mathrm{~h}$ prior to their first blood meal.

\section{Drug}

Ivermectin was prepared as described previously [9]. Powdered formulation of ivermectin compound was obtained from Sigma-Aldrich (St. Louis, MO, USA). Ivermectin was dissolved in dimethylsulfoxide (DMSO) to concentrations of $10 \mathrm{mg} / \mathrm{ml}$ and $20 \mu \mathrm{l}$ aliquots were frozen at $-20^{\circ} \mathrm{C}$. Ivermectin was thawed and serial dilutions were made in phosphate buffered saline (PBS) and $10 \mu \mathrm{l}$ was added to $990 \mu \mathrm{l}$ of blood to reach final concentration desired for mosquito membrane-feeding assays. Control blood meals consisted of previously frozen DMSO diluted in PBS to match the ratio of DMSO and PBS fed to mosquitoes in the ivermectin-containing blood meals.

\section{Blood}

Chicken blood to maintain the mosquito colonies was obtained from a local slaughter-house consistent with previous studies [29]. Blood for lethal concentration calculation experiments were drawn from healthy volunteers and malaria-infected patients into $10 \mathrm{ml}$ sodium heparin tubes (NH) (158 USP units, BD Vacutainer, Franklin Lakes, NJ, USA). Blood for lethal concentration experiments was stored at $4{ }^{\circ} \mathrm{C}$ and never more than 2 weeks post collection at the time of mosquito blood feeds. Plasmodium vivaxinfected patients were identified by microscopic examination of Giemsa-stained thick blood smears at Ministry of Health health centres and hospitals in Iquitos. Patients were transported to NAMRU-6, enrolled and venous blood (15-ml) was drawn on site for the ivermectin sporogony 
experiments following procedures approved by NAMRU-6 and Walter Reed Army Institute of Research Institutional Review Boards (NMRCD.2008.0004 and WRAIR\#2175) in compliance with all applicable Federal regulations governing the protection of human subjects. Blood for the ivermectin re-feeding experiments was collected from four healthy, non-malarious volunteers, as determined by microscopy and confirmed by a pre-optimized nested PCR assay [30, 31] (NAMRU6.2014.0009 and WRAIR\#2342).

\section{Ivermectin lethal concentration calculations}

Lethal concentration calculations for An. darlingi were performed as described previously [9]. Anopheles darlingi were blood fed multiple concentrations of ivermectin to determine the lethal concentration that killed $50 \%\left(\mathrm{LC}_{50}\right)$, $25 \%\left(\mathrm{LC}_{25}\right)$ and $5 \%\left(\mathrm{LC}_{5}\right)$ of the mosquitoes following previous methods $[18,20]$. Control blood meals consisted of DMSO diluted in PBS to match the concentration found in the highest ivermectin treatment group in each replicate. After blood feeding via a membrane feeder, blood-fed mosquitoes were gently aspirated from the feeding container and transferred to clean, 250-ml, cardboard containers with access to $10 \%$ sucrose and kept in the infection insectary room at $24.8 \pm 1.0{ }^{\circ} \mathrm{C}$ and $62.1 \pm 6.7 \%$ relative humidity, on a 12-h light:12-h dark photoperiod. Mosquito survivorship was monitored for 7 days, every $24 \mathrm{~h}$ dead mosquitoes were removed and recorded and on day 7 all remaining mosquitoes were frozen and counted as alive.

\section{Effect of ivermectin on Plasmodium vivax sporogony}

Plasmodium vivax-infected blood was collected from malaria-infected patients as described above. Ivermectin at $\mathrm{LC}_{50}, \mathrm{LC}_{25}$ and $\mathrm{LC}_{5}$ concentrations and pair-matched DMSO controls were added to $1 \mathrm{ml}$ of whole blood and an additional $1 \mathrm{ml}$ of whole blood without ivermectin or DMSO control were fed to approximately $100 \mathrm{An}$. darlingi per 2.5-1 plastic container. Unfed mosquitoes were removed from the container and discarded. Blood-fed mosquitoes were left in the container and provided with $10 \%$ sucrose solution. Mosquitoes infected with $P$. vivax were securely maintained in the infection insectary room.

Mosquitoes were dissected 7 days post parasite ingestion to enumerate oocysts. Midguts were dissected with minuten pins into saline on a microscope slide and stained with $0.1 \%$ mercurochrome and viewed at $40 \times$ magnification with a compound microscope to determine oocyst prevalence and intensity. Approximately 25 mosquitoes were dissected from each control and treatment group.

\section{Ivermectin inhibition of time to re-feed}

Four ivermectin concentrations predicted to occur at 4,12 , 36 , and $60 \mathrm{~h}$ post ingestion of the $200 \mu \mathrm{g} / \mathrm{kg}$ dose [32] were determined as described previously [20]. Blood was drawn from the healthy volunteers and mixed with the four ivermectin concentrations and a DMSO control matched to the highest ivermectin concentration. One $\mathrm{ml}$ of blood for each concentration was offered to $100 \mathrm{An}$. darlingi females via a membrane feeder. Twenty fully engorged females from each concentration were individually transferred to separate $50-\mathrm{ml}$ conical tubes. Each tube had cotton padding and filter paper placed on the bottom of the tube and moistened with $5 \mathrm{ml}$ of distilled water, and the top of the tube was sealed with mesh netting. Mosquitoes were maintained in the adult insectary room and held without access to sugar for the remainder of the experiment. Every $24 \mathrm{~h}$ the volunteers returned to NAMRU- 6 to re-feed the mosquitoes. Volunteers laid their forearms across the tops of the $50-\mathrm{ml}$ tubes for $5 \mathrm{~min}$. Care was taken to ensure that volunteers blood fed only the mosquitoes that ingested their original blood samples. Once all the mosquitoes had been given the opportunity to re-feed they were investigated visually for blood meal ingestion or death by shining a bright headlamp onto the mosquito. Any blood fed or dead mosquitoes were removed from the experiment and recorded. Volunteers returned to NAMRU-6 for 12 consecutive days for mosquito re-feeding opportunities. Any mosquitoes alive at the end of the experiment were recorded (NAMRU6.2014.0009 and WRAIR\#2342).

\section{Statistical analysis}

Mosquito survival and sporontocidal results were analyzed as described previously [9]. A non-linear mixed effects model with Probit analysis was used to calculate 7-day- $\mathrm{LC}_{50},-\mathrm{LC}_{25}$ and $-\mathrm{LC}_{5}$ values with Statistical Analysis Software (SAS Institute, Inc., Cary, NC, USA) [20]. Hazard ratios for mosquito mortality at day 7 post-blood meal were calculated using Poisson regression analysis with STATA version 12.1 (Stata Corp, LLC, College Station, TX, USA). Oocyst prevalence (i.e., proportion of infected mosquitoes) was compared by Fishers Exact test. Oocyst intensity (i.e., number of oocysts per infected mosquito) was compared by the Mann-Whitney U test.

In the re-feeding experiment, mosquitoes that died instead of re-blood feeding, or survived to the end of the 12 days were censored data (up-ticks marked on each graph line). Replicates were pooled and analysed by the Logrank Test (Mantel-Cox method; proportional hazards model) and the hazard ratio with $95 \%$ confidence intervals. The Fisher's Exact, Mann-Whitney U, and Logrank test analyses were performed with Prism 7 (GraphPad Software, Inc, San Diego, CA, USA).

\section{Results}

Ivermectin lethal concentration calculations

A total of 6161 mosquitoes and 13 replicates were used to calculate the lethal concentration of ivermectin. The 
An. darlingi ivermectin lethal concentrations and 95\% fiducial limits were estimated at day 7 as: $\mathrm{LC}_{50}=43.2 \mathrm{ng} /$ $\mathrm{ml}[37.5,48.6], \mathrm{LC}_{25}=27.8 \mathrm{ng} / \mathrm{ml}[20.4,32.9]$, and $\mathrm{LC}_{5}=14.8 \mathrm{ng} / \mathrm{ml}[7.9,20.2]$. All ivermectin concentrations had significantly increased hazard of mortality compared to the control group except for 15, 12, 10, 8, and $4 \mathrm{ng} / \mathrm{ml}$, while 12,8 and $4 \mathrm{ng} / \mathrm{ml}$ had significantly reduced hazard for mortality (Table 1 ).

\section{Effect of ivermectin on Plasmodium vivax sporogony}

When ivermectin and $P$. vivax were co-ingested by $A n$. darlingi it reduced oocyst prevalence at the ivermectin $\mathrm{LC}_{50}$ by $22.6 \%\left(\chi^{2}=10.32, P=0.0014\right.$, reps $\left.=7, \mathrm{n}=287\right)$ and $\mathrm{LC}_{25}$ by $17.1 \%\left(\chi^{2}=5.16, P=0.0314\right.$, reps $=7$, $\mathrm{n}=285)$, and increased oocyst prevalence but not significantly at the $\mathrm{LC}_{5}$ by $11.3 \%\left(\chi^{2}=1.95, P=0.1918\right.$, reps $=7, \mathrm{n}=283$ ) (Fig. 2). Mean oocyst intensity was reduced slightly at the $\mathrm{LC}_{50}$ by $2.3 \%(P=0.6914$, reps $=7$, $\mathrm{n}=196)$, increased at the $\mathrm{LC}_{25}$ by $37.3 \%(P=0.1838$, reps $=7, \mathrm{n}=194)$, and was reduced slightly at the $\mathrm{LC}_{5}$ by 4.6\% $(P=0.8595$, reps $=7, \mathrm{n}=200)$ (Fig. 3 ) but none of these trends was significant.

\section{Ivermectin inhibition of time to re-feed}

The ivermectin concentrations used for the re-feeding experiment were estimated from a previous clinical trial [32] at $4-\mathrm{h}=48.7 \mathrm{ng} / \mathrm{ml}, 12-\mathrm{h}=26.9 \mathrm{ng} /$ $\mathrm{ml}, 36-\mathrm{h}=10.6 \mathrm{ng} / \mathrm{ml}$, and $60-\mathrm{h}=6.3 \mathrm{ng} / \mathrm{ml}$. The time to re-feed was delayed in $A n$. darlingi that ingested the $4-\mathrm{h}(48.7 \mathrm{ng} / \mathrm{ml})\left(\chi^{2}=10.11, P=0.0015\right.$,

Table 1 Hazard of mosquito mortality post ivermectin blood meal

\begin{tabular}{llll}
\hline Conc. & IRR & {$[95 \% \mathrm{Cl}]$} & P value \\
\hline 70 & 5.7 & {$[4.2-7.7]$} & $<0.0001$ \\
65 & 5.0 & {$[3.8-6.4]$} & $<0.0001$ \\
60 & 4.7 & {$[3.6-6.1]$} & $<0.0001$ \\
50 & 4.1 & {$[3.3-5.0]$} & $<0.0001$ \\
45 & 2.6 & {$[2.0-3.4]$} & $<0.0001$ \\
40 & 3.0 & {$[2.4-3.7]$} & $<0.0001$ \\
35 & 2.1 & {$[1.6-2.7]$} & $<0.0001$ \\
30 & 2.4 & {$[1.9-3.1]$} & $<0.0001$ \\
25 & 2.0 & {$[1.4-2.8]$} & $<0.0001$ \\
20 & 1.6 & {$[1.3-2.1]$} & $<0.0001$ \\
15 & 1.2 & {$[0.9-1.6]$} & 0.27 \\
12 & 0.5 & {$[0.3-0.9]$} & 0.018 \\
10 & 0.9 & {$[0.6-1.3]$} & 0.567 \\
8 & 0.4 & {$[0.2-0.7]$} & 0.004 \\
4 & 0.4 & {$[0.2-0.7]$} & 0.002 \\
\hline
\end{tabular}

Conc. concentration of ivermectin imbibed in $\mathrm{ng} / \mathrm{ml}, I R R$ incidence rate ratio of mortality at day 7 between each treatment group divided by the control group, 95\% Cl 95\% confidence intervals

Significant $P$ values $(P<0.05)$ are in italic
$\mathrm{HR}=2.961[1.631-5.377], \mathrm{n}=287)$ and $12-\mathrm{h}(26.9 \mathrm{ng} /$ ml) $\left(\chi^{2}=6.072, P=0.0137, \mathrm{HR}=1.987\right.$ [1.154-3.422], $\mathrm{n}=151)$, but was not delayed following ingestion of $36-\mathrm{h}(10.6 \mathrm{ng} / \mathrm{ml})\left(\chi^{2}=0.469, P=0.4935, \mathrm{HR}=1.043\right.$ $[0.646-1.684], \mathrm{n}=156)$, nor $60-\mathrm{h}(6.3 \mathrm{ng} / \mathrm{ml})\left(\chi^{2}=1.502\right.$, $P=0.2203, \mathrm{HR}=1.355$ [0.817-2.248], $\mathrm{n}=145)$ (Fig. 4).

\section{Discussion}

These findings indicate that the primary Amazonian malaria vector, $A n$. darlingi, is susceptible to ivermectin compound at human-relevant concentrations (Fig. 1). The An. darlingi ivermectin 7-day- $\mathrm{LC}_{50}=43.2 \mathrm{ng} / \mathrm{ml}$ is roughly equal to another South American malaria vector, Anopheles aquasalis 5-day- $\mathrm{LC}_{50}=47.0 \mathrm{ng} / \mathrm{ml}$ [10]. This demonstrates that ivermectin can alter the most influential variable for vectorial capacity, the daily probability of adult survivorship [33], in two important malaria vectors in South America. Recent ivermectin pharmacokinetic modelling [9] suggests that the $400-\mu \mathrm{g} / \mathrm{kg}$ dose may be the ideal minimal MDA dose to target both $A n$. darlingi and An. aquasalis in South America. Ivermectin at the $400-\mu \mathrm{g} / \mathrm{kg}$ dose is now recommended in some instances for lymphatic filariasis MDAs [34], and repeated doses every 2 weeks for 12 weeks were shown to be well tolerated in a trial in Brazil [35] and Sri Lanka [36].

The sporontocidal effect of ivermectin compound against $P$. vivax in An. darlingi significantly, albeit modestly, reduced oocyst prevalence at the $\mathrm{LC}_{50}$ and $\mathrm{LC}_{25}$ but not the $\mathrm{LC}_{5}$ (Fig. 2) and did not reduce oocyst intensity at any concentration (Fig. 3). This is surprising when compared to recent sporontocidal results of ivermectin against $P$. vivax oocyst prevalence and intensity reductions at the $\mathrm{LC}_{25}$ and $\mathrm{LC}_{5}$ in Anopheles dirus and Anopheles minimus [9]. Serum replacement from malaria naïve donors was not performed in the current study with $A n$. darlingi, which may explain some of the differences in ivermectin sporontocidal effect observed between studies with $P$. vivax. Previously, ivermectin $\mathrm{LC}_{25}$ was shown to be sporontocidal against cultured $P$. falciparum NF54 in $A n$. gambiae, reducing oocyst prevalence but not intensity $[18,19]$. Differences in ivermectin sporontocidal effect may be partially explained by differences in vector biology and physiology as An. darlingi belongs to the New World Nyssorhynchus subgenus while An. dirus, An. minimus, and An. gambiae belong to the Cellia subgenus. There is a shorter co-evolutionary history between $P$. vivax and New World Anopheles, when the parasite was possibly introduced from southern Asia in pre-Columbian times or from Europe in post-Columbian times [37]. It may be that these different vectors have different rates of peritrophic matrix formation which can be impacted by ivermectin [18] or different microbiota present in the colonized mosquitoes which could possibly be affected 


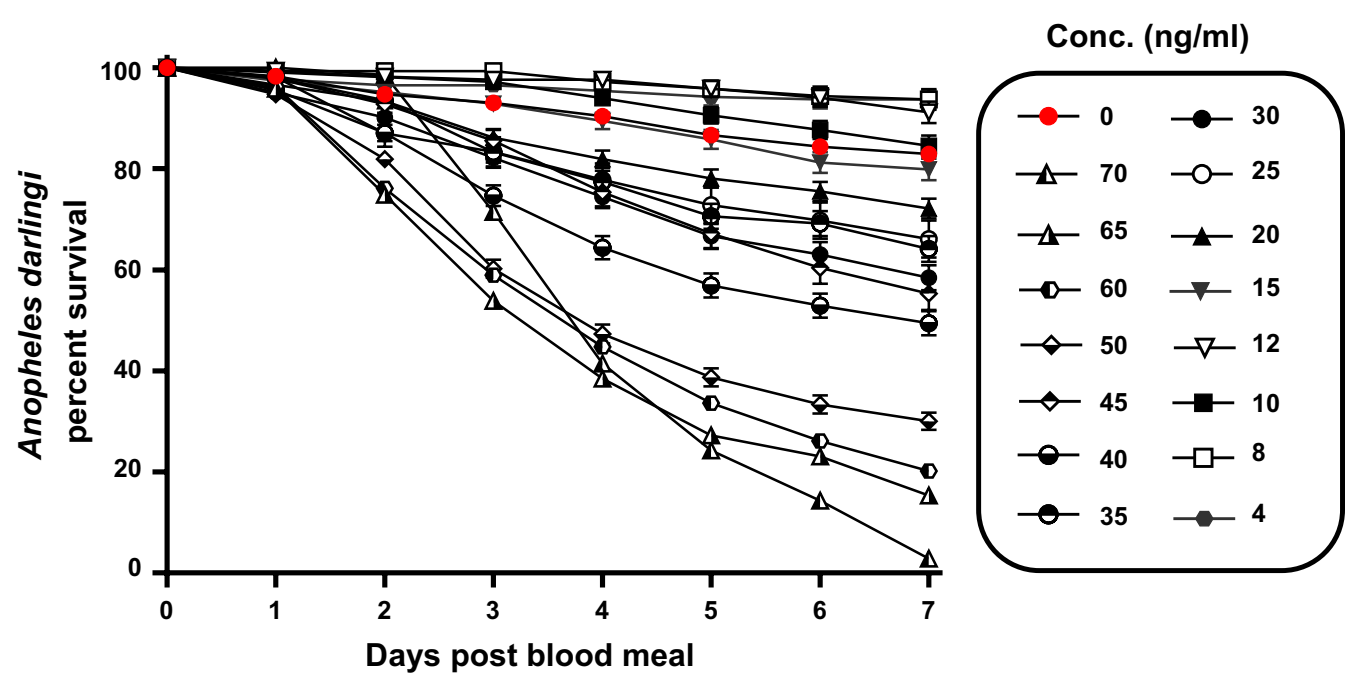

Fig. 1 Anopheles darlingi survival post ingestion of ivermectin by day. Boxed legends represent the concentrations of ivermectin imbibed. Not all concentrations included in the lethal concentration analyses are displayed here. Each line represents 1-13 replicates with standard error

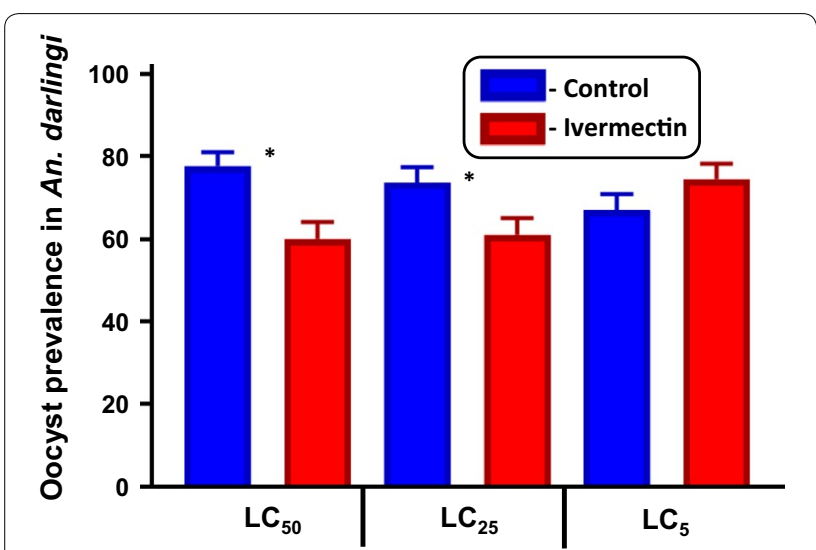

Fig. 2 Plasmodium vivax oocyst prevalence in Anopheles darlingi when ivermectin $\mathrm{LC}_{50}, \mathrm{LC}_{25}$ and $\mathrm{LC}_{5}$ co-ingested with parasites. Oocyst prevalence was significantly reduced at the $L C_{50}$ and $L C_{25}$ but not the $\mathrm{LC}_{5}$ concentrations as determined by Fishers Exact test

by ivermectin and in turn alter Plasmodium infection outcomes [9]. Due to this limited sporontocidal effect of ivermectin compound in An. darlingi at point of parasite co-ingestion, effects of ivermectin ingested at different time points from parasites were not investigated.

Ivermectin significantly delayed the time to re-feed for An. darlingi at the 4- and 12-h concentrations but not at the 36- or 60-h concentrations (Fig. 4). The time to re-feed is the second-most important variable in vectorial capacity, thus any delay at sub-lethal concentrations has ability to suppress transmission in the field [33]. Furthermore, a delay in An. darlingi time to re-feed may decrease the likelihood of survival which would compound mortality and further suppress Plasmodium transmission in the Amazon. A similar delay in time to re-feed after ivermectin ingestion was observed for $A n$. gambiae [20], which may be caused by the ivermectin knockdown and delay in recovery effects also observed in An. gambiae [38].

The mechanism of action for ivermectin to delay Anopheles time to re-feed has not been characterized. Interestingly, it was demonstrated in the dung beetle, Scarabaeus cicatricosus, that ivermectin ingestion in dung diet decreased olfactory response and locomotor function, suggesting a negative impact on insect basic biological activities, such as food or mate-seeking [39]. In An. gambiae, the glutamate-gated chloride ion channel, which is the target of ivermectin, was found in the thoracic ganglia, Johnston's organ, antennal segments, optic lobe and supraesophageal ganglion [40]. The thoracic ganglia contain motor neurons for regulating locomotor function of flight and leg muscles while the Johnston's organ regulates flight coordination, which may explain the paralytic effect frequently observed following ivermectin ingestion by mosquitoes [38, 40]. The antenna, optic lobe and supraesophageal ganglion work in concert to regulate chemosensory and visual cues for host location, thus ingestion of ivermectin may impair the ability of mosquitoes to locate their host [40]. Moreover, reduced olfactory sensitivity towards ivermectin-treated animal host cues was recorded in the midge Culicoides imicola [41], further suggesting that ivermectin could inhibit host attraction and biting in haematophagous insects. Electroantennogram studies characterizing electrophysiological responses to host odour stimuli have not 


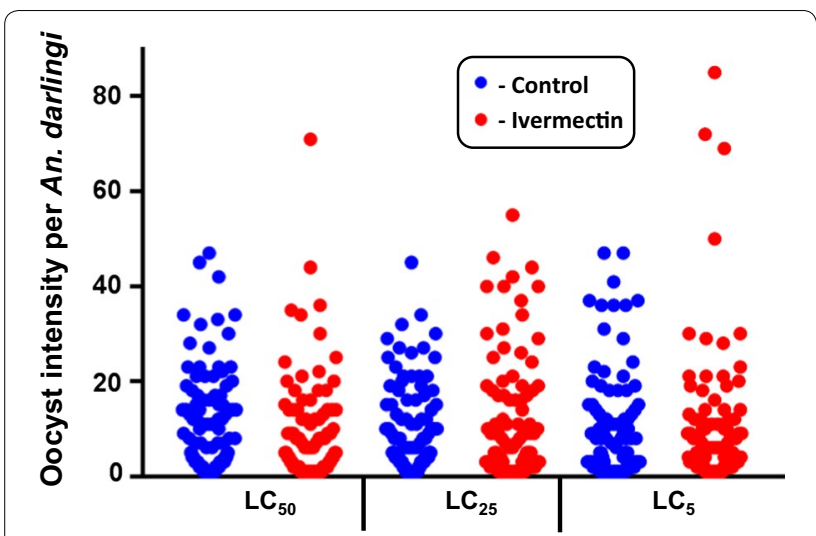

Fig. 3 Plasmodium vivax oocyst intensity in Anopheles darlingi when ivermectin $\mathrm{LC}_{50}, \mathrm{LC}_{25}$ and $\mathrm{LC}_{5}$ co-ingested with parasites. Oocyst intensity was not reduced at any concentration as determined by Mann-Whitney U test

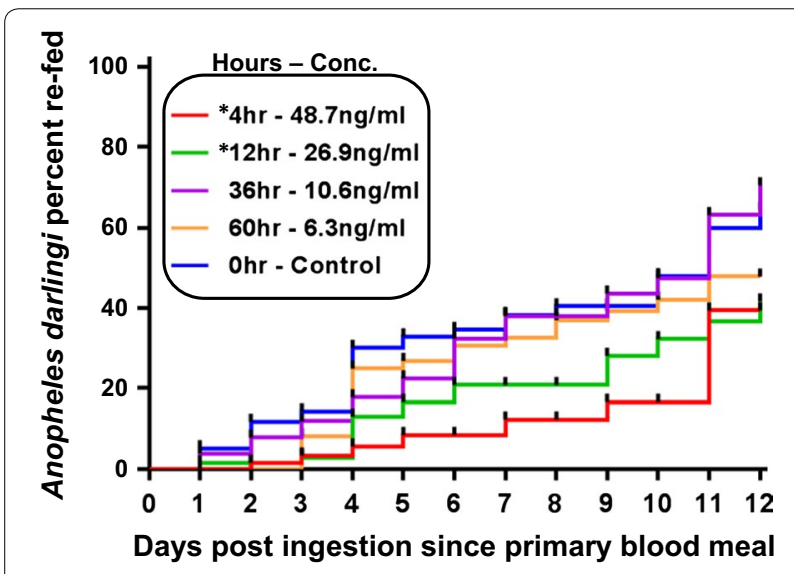

Fig. 4 Anopheles darlingi time to re-feed following ingestion of ivermectin. Time to re-feed was significantly delayed at the 4-h (48.7 ng/ $\mathrm{ml})$ and $12-\mathrm{h}(26.9 \mathrm{ng} / \mathrm{ml})$ but not the $36-\mathrm{h}(10.6 \mathrm{ng} / \mathrm{ml})$ or $60-\mathrm{h}$ $(6.3 \mathrm{ng} / \mathrm{ml})$ concentrations as determined by Logrank Test (MantelCox method)

been performed in Anopheles that have ingested ivermectin. If insect olfactory detection mechanisms or other sensory capacities are impacted by ivermectin, then this will inhibit the ability of Anopheles to detect vertebrates when host-seeking, which could delay time to re-feed.

Ivermectin MDA campaigns conducted by OEPA demonstrate that repeated MDAs in Latin America are feasible at up to 3 month intervals. While the remoteness of some villages in the Amazon will make them difficult to contact, the successes being noted with ivermectin MDA in Yanomami indigenous populations in the Venezuelan Amazon are quite laudable [42]. Many people in areas of Latin America afflicted with malaria will likely have concomitant infections with numerous neglected tropical diseases (NTDs) that can be controlled with ivermectin such as lice, scabies, cutaneous larval migrans (CLM) [43], the soil-transmitted helminths (STHs) (e.g., Ascaris, Trichuris, and hookworm) [44, 45], and strongyloidiasis [46]. The OEPA once yearly ivermectin MDA reduced Strongyloides and Trichuris prevalence, but not Ascaris or hookworm in Ecuador [47] and Colombia [48]. Indeed, ivermectin can be quite effective against lice, scabies, CLM, STHs and strongyloidiasis when administered once [49] or twice within 7-10 days [50-52] and MDAs can be quite effective $[51,52]$. However, re-infection from the soil for CLM, STHs and Strongyloides, and reinfestation from untreated persons for scabies and lice can occur quickly [52]. This suggests that more frequent ivermectin MDAs to target malaria parasite transmission could have dramatic impact on numerous NTDs found in Latin America, and may improve compliance with MDAs for malaria control.

Plasmodium vivax has become the most prevalent malaria species in Latin America. Due to the relapsing nature and inability to identify persons with $P$. vivax hypnozoites, this species will be considerably more difficult to eliminate. Several field trials are under way to eliminate $P$. falciparum by administering MDAs with dihydroartemisinin-piperaquine and low-dose primaquine $[53,54]$. It has been observed that persons infected with $P$. falciparum also have dormant $P$. vivax hypnozoites that release after $P$. falciparum treatment [55-58]. Dihydroartemisinin-piperaquine is effective against blood stage $P$. vivax and the long half-life of piperaquine with once a month administrations can effectively suppress the frequent tropical $P$. vivax relapses at the blood stage [59]. Primaquine MDAs with the target of radical cure of $P$. vivax hypnozoites have been performed in several countries including: Afghanistan, Azerbaijan, Tajikistan, North Korea [60], Taiwan, Papua New Guinea, Solomon Islands, Tanzania, Nicaragua, Malaysia, Indonesia, China, Kyrgyzstan [61], Vanuatu [62], and Cambodia [63]. Since the total cumulative dose of primaquine provides radical cure of $P$. vivax hypnozoites [64] it is possible to space the primaquine MDAs every 7 [62] to 10 [63] days over several months. Ivermectin could be co-administered with primaquine MDAs every 7-10 days to achieve substantial suppression by Anopheles vectors for all Plasmodium species while specifically targeting $P$. vivax radical cure. Currently, clinical trials to investigate the safety and tolerability of ivermectin plus dihydroartemisininpiperaquine (NCT02568098) [65] and ivermectin plus primaquine (NCT02568098) are being conducted. If ivermectin can be safely co-administered with anti-malarial drugs during MDAs, then this has the potential to be a powerful malaria and vector control intervention in Latin America. 


\section{Conclusions}

Ivermectin reduces $A n$. darlingi survivorship, modestly inhibits development of $P$. vivax in the vector by reducing oocyst prevalence at the $\mathrm{LC}_{50}$ and $\mathrm{LC}_{25}$ but not intensity, and delays time to re-feed at human-relevant concentrations up to $12 \mathrm{~h}$ post drug ingestion. The ivermectin 400$\mu \mathrm{g} / \mathrm{kg}$ dose is likely the ideal minimal dose used during ivermectin MDA in Latin America. The success of the OEPA against onchocerciasis indicates that ivermectin MDAs can be effectively executed in Latin America. Numerous NTDs that are prevalent in Latin America could be affected by ivermectin MDAs. This suggests that ivermectin MDAs could be a powerful new tool to aid malaria elimination in Latin America and would likely be well received as a public health measure.

\section{Abbreviations \\ CLMs: cutaneous larval migrans; DMSO: dimethylsulfoxide; MDA: mass drug administration; NAMRU-6: Naval Medical Research Unit No. 6; NTDs: neglected tropical diseases; OEPA: Onchocerciasis Elimination Programme for the Ameri- cas; PBS: phosphate-buffered saline; STHs: soil-transmitted helminths. \\ Authors' contributions \\ KCK, KSE-V, VML-S and GMV designed experiments; KSE-V and VML-S con- ducted the experiments; KCK and GMV analysed data; GMV, CAS, GCB, RVG and S-BB provided reagents; KCK, KSE-V, VML-S, SD, ESS, GCB, RVG, S-BB, CAS and GMV wrote the manuscript. All authors read and approved the final manuscript.}

\section{Author details}

${ }^{1}$ Department of Entomology, Armed Forces Research Institute of Medical Sciences, 315/6 Rajvithi Road, Bangkok 10400, Thailand. ${ }^{2}$ Entomology Branch, Walter Reed Army Institute of Research, 503 Robert Grant Ave, Silver Spring, MD 20910, USA. ${ }^{3}$ Department of Entomology, U.S. Naval Medical Research Unit No. 6, Av. Venezuela block $36 \mathrm{~s} / \mathrm{n}$, Callao 2, Peru. ${ }^{4}$ Department of Parasitology, U.S. Naval Medical Research Unit No. 6, Av. Venezuela block 36 s/n, Callao 2, Peru. ${ }^{5}$ Infectious Diseases Directorate, Naval Medical Research Center, Silver Spring, MD 20910, USA. ${ }^{6}$ Department of International Health, Johns Hopkins Bloomberg School of Public Health, 615 N. Wolfe St., Rm. W5515, Baltimore, MD 21205, USA.

\section{Acknowledgements}

We thank all P. vivax-infected and healthy blood donors. We would like to acknowledge the help of the NAMRU-6 Departments of Entomology, Parasitology, and Virology staff, especially Drs. Chrystian Syles and Isabel Bazan for healthy volunteer enrollment and clinical evaluation; Miguel Vasquez, Geidin Chavez, Hugo Jaba, Luz Romero and Maria Bosantes for mosquito colony rearing; May Tello, Marlene Rios, Ericka Pinedo and Neyvis Cabrera for malaria patient enrollment; and Dolores Rimarachin, Greys Braga, and Leonila Ricopa for vivax malaria diagnosis confirmation. We thank Dr. Kesara Na-Bangchang for kindly providing the ivermectin data used to predict concentrations to feed mosquitoes in the re-feeding experiment. This work was performed while Kevin Kobylinski held a National Research Council Fellowship. This work was supported by Grant OPP1095931 from the Bill \& Melinda Gates Foundation.

\section{Competing interests}

The authors declare that they have no competing interests.

\section{Copyright statement}

Some authors of this manuscript are military service members and employees of the US Government. This work was prepared as part of their official duties. Title 17 U.S.C. $\$ 105$ provides that "Copyright protection under this Title is not available for any work of the United States Government". Title 17 U.S.C. $\S 101$ defines a US Government work as a work prepared by a military service member or employee of the US Government as part of that person's official duties.

\section{Disclaimer}

The views, opinions, or assertions expressed in this article are those of the authors and do not necessarily reflect the official policy or position of the Department of the Navy, Department of the Army, Department of Defense, nor the US Government.

\section{Publisher's Note}

Springer Nature remains neutral with regard to jurisdictional claims in published maps and institutional affiliations.

Received: 13 July 2017 Accepted: 16 November 2017

Published online: 21 November 2017

\section{References}

1. Vitor-Silva S, Siqueira A, Sampaio V, Guinovart C, Reyes-Lecca R, Melo G, et al. Declining malaria transmission in rural Amazon: changing epidemiology and challenges to achieve elimination. Malar J. 2016;15:266.

2. WHO. World malaria report 2016. Geneva: World Health Organization; 2016.

3. Sinka M, Rubio-Palis Y, Manguin S, Patil A, Temperley W, Gething P, et al. The dominant Anopheles vectors of human malaria in the Americas: occurence data, distribution maps and bionomic précis. Parasites Vectors. 2010;3:72.

4. Girod R, Gaborit P, Carinci R, Issaly J, Fouque F. Anopheles darlingi bionomics and transmission of Plasmodium falciparum, Plasmodium vivax and Plasmodium malariae in Amerindian villages of the Upper-Maroni Amazonian forest, French Guiana. Mem Inst Oswaldo Cruz. 2008;103:702-10.

5. Moreno J, Rubio-Palis Y, Páez E, Pérez E, Sánchez V. Abundance, biting behaviour and parous rate of anopheline mosquito species in relation to malaria incidence in gold-mining areas of southern Venezuela. Med Vet Entomol. 2007;21:339-49.

6. Hiwat H, Bretas G. Ecology of Anopheles darlingi root with respect to vector importance: a review. Parasites Vectors. 2011;4:177.

7. Moutinho P, Gil L, Cruz R, Ribolla P. Population dynamics, structure and behavior of Anopheles darlingi in a rural settlement in the Amazon rainforest of Acre, Brazil. Malar J. 2011;10:174

8. Gil L, Alves F, Zieler H, Salcedo J, Durlacher R, Cunha R, et al. Seasonal malaria transmission and variation of anopheline density in two distinct endemic areas in Brazilian Amazonia. J Med Entomol. 2003;40:636-41.

9. Kobylinski K, Ubalee R, Ponlawat A, Nitatsukprasert C, Phasomkulsolsil S, Wattanakul T, et al. Ivermectin susceptibility and sporontocidal effect in Greater Mekong Subregion Anopheles. Malar J. 2017;16:280.

10. Sampaio V, Beltrán T, Kobylinski K, Melo G, Lima J, Silva S, et al. Filling gaps on ivermectin knowledge: effects on the survival and reproduction of Anopheles aquasalis, a Latin American malaria vector. Malar J. 2016:15:491.

11. Chaccour C, Rabinovich N, Slater H, Canavati S, Bousema T, Lacerda M, et al. Establishment of the ivermectin research for malaria elimination network: updating the research agenda. Malar J. 2015;14:243.

12. Chaccour C, Kobylinski K, Bassat Q, Bousema T, Drakeley C, Alonso P, et al. Ivermectin to reduce malaria transmission: a research agenda for a promising new tool for elimination. Malar J. 2013;12:153.

13. Sylla M, Kobylinski K, Gray M, Chapman P, Sarr M, Rasgon J, et al. Mass drug administration of ivermectin in south-eastern Senegal reduces the survivorship of wild-caught, blood fed malaria vectors. Malar J. 2010:9:365.

14. Alout H, Krajacich B, Meyers J, Grubaugh N, Brackney D, Kobylinski K, et al. Evaluation of ivermectin mass drug administration for malaria transmission control across different West African environments. Malar J. 2014;13:417.

15. Bockarie M, Hii J, Alexander N, Bockarie F, Dagoro H, Kazura J, et al. Mass treatment with ivermectin for filariasis control in Papua New Guinea: impact on mosquito survival. Med Vet Entomol. 1999:13:120-3. 
16. Kositz C, Talina J, Diau J, Asugeni R, Whitehorn C, Mabey D, et al. Incidental mosquitocidal effect of an ivermectin mass drug administration on Anopheles farauti conducted for scabies control in the Solomon Islands. Trans R Soc Trop Med Hyg. 2017;111:97-101

17. Kobylinski K, Sylla M, Chapman P, Sarr M, Foy B. Ivermectin mass drug administration to humans disrupts malaria parasite transmission in Senegalese villages. Am J Trop Med Hyg. 2011;85:3-5.

18. Kobylinski K, Foy B, Richardson J. Ivermectin inhibits the sporogony of Plasmodium falciparum in Anopheles gambiae. Malar J. 2012;11:381.

19. Kobylinski K, Alout H, Foy B, Clements A, Adisakwattana P, Swierczewski $B$, et al. Rationale for the coadministration of albendazole and ivermectin to humans for malaria parasite transmission control. Am J Trop Med Hyg. 2014;91:655-62

20. Kobylinski K, Deus K, Butters M, Hongyu T, Gray M, da Silva I, et al. The effect of oral anthelmintics on the survivorship and re-feeding frequency of anthropophilic mosquito disease vectors. Acta Trop. 2010;116:119-25.

21. Cupp E, Sauerbrey M, Richards F. Elimination of human onchocerciasis: history of progress and current feasibility using ivermectin (Mectizan ${ }^{\circledR}$ ) monotherapy. Acta Trop. 2011;120:S100-8.

22. Lovato R, Guevara A, Guderian R, Proaño R, Unnasch T, Criollo H, et al. Interruption of infection transmission in the Onchocerciasis focus of Ecuador leading to the cessation of ivermectin distribution. PLoS Negl Trop Dis. 2014;5:2821.

23. Rodríguez-Pérez M, Fernández-Santos N, Orozco-Algarra M, RodríguezAtanacio J, Domínguez-Vázquez A, Rodríguez-Morales K, et al. Elimination of onchocerciasis from Mexico. PLoS Negl Trop Dis. 2015:9:0003922.

24. WHO. Progress towards eliminating onchocerciasis in the WHO Region of the Americas: verification by $\mathrm{WHO}$ of elimination of transmission in Colombia. Wkly Epidemiol Rec. 2013:88:381-5.

25. WHO. Progress towards eliminating onchocerciasis in the WHO Region of the Americas: verification of elimination of transmission in Guatemala. Wkly Epidemiol Rec. 2016;91:501-5.

26. Duke B, Zea-Flores G, Castro J, Cupp E, Munoz B. Effects of three-month doses of ivermectin on adult Onchocerca volvulus. Am J Trop Med Hyg. 1992;46:189-94

27. Cupp E, Cupp M. Impact of ivermectin community-level treatments on elimination of adult Onchocerca volvulus when individuals receive multiple treatments per year. Am J Trop Med Hyg. 2005;73:1159-61.

28. Slater H, Walker P, Bousema T, Okell L, Ghani A. The potential impact of adding ivermectin to a mass treatment intervention to reduce malaria transmission: a modelling study. J Infect Dis. 2014;210:1972-80.

29. Villarreal-Treviño C, Vásquez G, López-Sifuentes V, Escobedo-Vargas K, Huayanay-Repetto A, Linton Y, et al. Establishment of a free-mating, longstanding and highly productive laboratory colony of Anopheles darlingi from the Peruvian Amazon. Malar J. 2015;14:227.

30. Baldeviano G, Okoth S, Arrospide N, Gonzalez R, Sánchez J, Macedo S, et al. Molecular epidemiology of Plasmodium falciparum malaria outbreak, Tumbes, Peru, 2010-2012. Emerg Infect Dis. 2015;21:797-803.

31. Singh B, Bobogare A, Cox-Singh J, Snounou G, Abdullah M, Rhaman $H$. A genus- and species-specific nested polymerase chain reaction malaria detection assay for epidemiologic studies. Am J Trop Med Hyg. 1999;60:687-92

32. Na-Bangchang K, Kietinun S, Pawa K, Hanpitakpong W, Na-Bangchang C, Lazdins J. Assessments of pharmacokinetic drug interactions and tolerability of albendazole, praziquantel and ivermectin combinations. Trans $\mathrm{R}$ Soc Trop Med Hyg. 2006;100:335-45.

33. Black W, Moore C. Population biology as a tool to study vector-borne diseases. In: Marquardt W, editor. Biology of disease vectors. San Diego: Elsevier Academic Press; 2005. p. 187-206.

34. Merck Sharp \& Dohme (France): Mectizan Package Insert. 2014

35. Dreyer G, Addiss D, Norões J, Amaral F, Rocha A, Coutinho A. Ultrasonographic assessment of the adulticidal efficacy of repeat high-dose ivermectin in bancroftian filariasis. Trop Med Int Health. 1996;1:427-32.

36. Ismail M, Weil G, Jayasinghe K, Premaratne U, Abeyewickreme W, Rajaratnam $\mathrm{H}$, et al. Prolonged clearance of microfilaraemia in patients with bancroftian filariasis after multiple high doses of ivermectin or diethylcarbamazine. Trans R Soc Trop Med Hyg. 1996;90:684-8.

37. Carter R. Speculations on the origins of Plasmodium vivax malaria. Trends Parasitol. 2003;19:214-9.
38. Butters M, Kobylinski K, Deus K, da Silva I, Gray M, Sylla M, et al. Comparative evaluation of systemic drugs for their effects against Anopheles gambiae. Acta Trop. 2012;121:34-43.

39. Verdú J, Cortez V, Ortiz A, González-Rodríguez E, Martinez-Pinna J, Lumaret J-P, et al. Low doses of ivermectin cause sensory and locomotor disorders in dung beetles. Sci Rep. 2015;5:13912.

40. Meyers J, Gray M, Kuklinski W, Johnson L, Snow C, Black W, et al. Characterization of the target of ivermectin, the glutamate-gated chloride channel, from Anopheles gambiae. J Exp Biol. 2015;218:1478-86.

41. Sollai G, Solari P, Masala C, Crnjar R, Liscia A. Effects of avermectins on olfactory responses of Culicoides imicola (Diptera: Ceratopogonidae). J Med Entomol. 2007;44:656-9.

42. Botto C, Basañez M-G, Escalona M, Villamizar N, Noya-Alarcón O, Cortez J, et al. Evidence of suppression of onchocerciasis transmission in the Venezuelan Amazonian focus. Parasites Vectors. 2016;9:40.

43. Heukelbach J, Feldmeier H. Ectoparasites - the underestimated realm. Lancet. 2004;363:889-91.

44. Cabada M, Lopez M, Arque E, Clinton WA. Prevalence of soil-transmitted helminths after mass albendazole administration in an indigenous community of the Manu jungle in Peru. Pathog Glob Health. 2014;108:200-5.

45. Valverde J, Gomes-Silva A, de Carvalho Moreira C, Leles de Souza D, Jaeger L, Martins P, et al. Prevalence and epidemiology of intestinal parasitism, as revealed by three distinct techniques in an endemic area in the Brazilian Amazon. Ann Trop Med Parasitol. 2011;105:413-24.

46. Buonfrate D, Mena M, Angheben A, Requena-Mendez A, Muñoz J, Gobbi $F$, et al. Prevalence of strongyloidiasis in Latin America: a systematic review of the literature. Epidemiol Infect. 2015;143:452-60.

47. Anselmi M, Buonfrate D, Espinoza A, Prandi R, Marquez M, Gobbo M, et al. Mass administration of ivermectin for the elimination of Onchocerciasis significantly reduced and maintained low the prevalence of Strongyloides stercoralis in Esmeraldas, Ecuador. PLoS Negl Trop Dis. 2015;9:0004150.

48. Knudson A, Ariza Y, López M, Fajardo O, Reyes P, Moncada L, et al. The effect of ivermectin on geohelminth frequency (i.e. as used in the onchocerciasis control program in Colombia). Rev Salud Publica. 2012;14:681-94.

49. Schuster A, Lesshafft $H$, Reichert F, Talhari S, de Oliveira S, Ignatius R, et al. Hookworm-related cutaneous larva migrans in Northern Brazil: resolution of clinical pathology after a single dose of ivermectin. Clin Infect Dis. 2013;57:1155-7.

50. Worth C, Heukelbach J, Fengler G, Walter B, Liesenfeld O, Hengge U, et al. Acute morbidity associated with scabies and other ectoparasites rapidly improves after treatment with ivermectin. Pediatr Dermatol. 2012;29:430-6

51. Heukelbach J, Wilcke T, Winter B, de Oliveira F, Moura R, Harms G, et al. Efficacy of ivermectin in a patient population concomitantly infected with intestinal helminths and ectoparasites. Arzneimittelforschung. 2004;54:416-21.

52. Heukelbach J, Winter B, Wilcke T, Muehlen M, Albrecht S, De Oliveira F, et al. Selective mass treatment with ivermectin to control intestinal helminthiases and parasitic skin diseases in a severely affected population. Bull World Health Organ. 2004;82:563-71.

53. von Seidlein $L$, Dondorp A. Fighting fire with fire: mass antimalarial drug administrations in an era of antimalarial resistance. Expert Rev Anti Infect Ther. 2015;13:715-30.

54. Eisele T, Bennett A, Silumbe K, Finn T, Chalwe V, Kamuliwo M, et al. Short-term impact of mass drug administration with dihydroartemisinin plus piperaquine on malaria in Southern Province Zambia: a clusterrandomized controlled trial. J Infect Dis. 2016;214:1831-9.

55. Lin J, Bethell D, Tyner S, Lon C, Shah N, Saunders D, et al. Plasmodium falciparum gametocyte carriage is associated with subsequent Plasmodium vivax relapse after treatment. PLoS ONE. 2011;6:18716.

56. Douglas N, Nosten F, Ashley E, Phaiphun L, van Vugt M, Singhasivanon P, et al. Plasmodium vivax recurrence following falciparum and mixed species malaria: risk factors and effect of antimalarial kinetics. Clin Infect Dis. 2011;52:612-20.

57. Looareesuwan S, White N, Bunnag D, Chittamas S, Harinasuta T. High-rate of Plasmodium vivax relapse following treatment of falciparum-malaria in Thailand. Lancet. 1987;2:1052-5.

58. Smithuis F, Kyaw M, Phe O, Win T, Aung P, Oo A, et al. Effectiveness of five artemisinin combination regimens with or without primaquine 
in uncomplicated falciparum malaria: an open-label randomised trial. Lancet Infect Dis. 2010;10:673-81.

59. Lwin K, Phyo A, Tarning J, Hanpitakpong W, Ashley E, Lee S, et al. Randomized, double-blind, placebo-controlled trial of monthly versus bimonthly dihydroartemisinin-piperaquine chemoprevention in adults at high risk of malaria. Antimicrob Agents Chemother. 2012;56:1571-7.

60. Kondrashin A, Baranova A, Ashley E, Recht J, White N, Sergiev V. Mass primaquine treatment to eliminate vivax malaria: lessons from the past. Malar J. 2014;13:51.

61. Shanks D. Control and elimination of Plasmodium vivax. Adv Parasitol. 2012:80:301-41.

62. Kaneko A, Taleo G, Kalkoa M, Yamar S, Kobayakawa T, Björkman A. Malaria eradication on islands. Lancet. 2000;356:1560-4.
63. Song J, Socheat D, Tan B, Dara P, Deng C, Sokunthea S, et al. Rapid and effective malaria control in Cambodia through mass administration of artemisinin-piperaquine. Malar J. 2010;9:57.

64. Leslie T, Mayan I, Mohammed N, Erasmus P, Kolaczinski J, Whitty C, et al. A randomised trial of an eight-week, once weekly primaquine regimen to prevent relapse of Plasmodium vivax in Northwest Frontier Province, Pakistan. PLoS ONE. 2008;3:2861.

65. Smit M, Ochomo E, Aljayyoussi G, Kwambai T, Abong'o B, Bayoh N, et al. Efficacy and safety of high-dose ivermectin for reducing malaria transmission (IVERMAL): protocol for a double-blind, randomized, placebo-controlled, dose-finding trial in Western Kenya. JMIR Res Protoc. 2016;5:213.

\section{Submit your next manuscript to BioMed Central and we will help you at every step:}

- We accept pre-submission inquiries

- Our selector tool helps you to find the most relevant journal

- We provide round the clock customer support

- Convenient online submission

- Thorough peer review

- Inclusion in PubMed and all major indexing services

- Maximum visibility for your research

Submit your manuscript at www.biomedcentral.com/submit 